\title{
Experiences from Interior Super Insulation of a Brick Wall from the 1800s
}

\author{
Pär Johansson and Paula Wahlgren
}

\author{
Department of Architecture and Civil Engineering, Chalmers University of Technology, SE-412 96
}

Gothenburg, Sweden, par.johansson@chalmers.se

\begin{abstract}
Many brick buildings in Sweden today face a large need for renovation measures to prolong their service life and make other uses possible. Conventional thermal insulation materials, such as fibre glass and EPS, demand a thick layer of insulation to reach the energy targets. Super insulation materials, such as vacuum insulation panels (VIP) and aerogel blankets (AB), are thermal insulation components with a 3-10 times higher thermal resistance than conventional insulation materials. In this study, the effect of interior insulation using super insulation materials is investigated, using experiences from a case study in a brick wall from the 1800s. Earlier research has shown that interior insulation decreases the drying-out capacity of an exterior wall and increases the risk for freeze-thaw damages in brick walls. The case study building is an industrial building from 1896 with $470 \mathrm{~mm}$ homogeneous brick masonry walls insulated with both aerogel insulation and with vacuum insulation panels. Six heat flux sensors were installed in the wall and used to evaluate the thermal resistance of the wall with and without insulation. The initial measurements showed that the rate of water flow in the bricks is approximately three times higher than that in modern bricks. The average calculated U-value was reduced by $70 \%$ for the $A B$ and $81 \%$ for the VIP layers, while measurements at the three occasions gave a reduction of $72-83 \%$ for the $A B$ and $72-84 \%$ for the VIP layers, i.e. in the same order of magnitude.
\end{abstract}

Keywords: Interior Insulation, Vacuum Insulation Panel, Aerogel, Thermal Inertia.

\section{Introduction}

The construction sector is responsible for approximately $37 \%$ of the energy use in Sweden (Boverket, 2019). Around 78\% of this energy is accounted to heating and cooling of buildings and the rest to construction, renovation and demolition activities. The amount of energy for heating has increased the last years and was 7\% higher in 2016 than the average energy use in the preceding 10-year period and 8\% higher than the previous year (Boverket, 2019). Around $25 \%$ of the energy for heating is used in the part of the building stock built before 1941 (Swedish Energy Agency, 2014). The focus on energy savings in society to mitigate carbon emissions, has led to implementations of several European directives on energy performance in buildings. The current intention is to enforce national renovation strategies of buildings to reach low or zero carbon dioxide emissions from the building industry by 2050 . There is also an increased focus on embodied energy and life cycle assessment of materials that are used in the construction sector (Boverket, 2018).

There are several challenges associated with decreasing the energy use in existing buildings, especially in buildings located in areas of national interest for cultural heritage or listed buildings. The conflict between energy efficiency and heritage values in buildings have been touched upon on in several research projects and are common in everyday practice when renovating buildings for improved energy performance. Here, one of the challenges is to reduce the energy use while not tampering with the character defining elements of a building, such as the expression of the façade, the foundation, the volume of the building, the decoration of the 
façade, the windows and the window frames. Generally, walls can be insulated either on the interior or exterior side. Concerning moisture performance, external insulation is beneficial as this increases the temperature of the original construction. Unfortunately, this is not allowed in many listed buildings. Therefore, interior insulation may be the only solution. Earlier research has shown that interior insulation decreases the drying-out capacity in the outer wall and increases the risk for freeze-thaw damages in brick walls (Johansson et al., 2014). Interior insulation will also negatively affect the thermal storage capacity of the building and change the interior appearance of the walls, which is particularly important to consider for historical and/or listed buildings (Johansson et al., 2019).

In this paper, a study based on a case study building of using super insulation materials in retrofitting of exterior walls is presented. The case study building, the background and planning of the study was presented in Johansson and Wahlgren (2018). In Johansson et al. (2019), the focus of the study was on the cultural heritage aspects and the conflict between energy efficiency and heritage values in buildings. Here, various parameters influencing the heat flux through the wall is discussed based on calculations and measurements from three separate occasions during the year. Two of these occasions were presented in Johansson et al. (2019) and in this paper measurements from the autumn season is added. These measurements add new information since the wall now has been heated for a longer time period while the average temperature is the same as in the spring season. The aim of the project is to propose practical guidelines and recommendations for using super insulation materials in listed buildings. This research is based on evaluation of vacuum insulation panels (VIP) and aerogel blankets (AB) in a case study building in Gothenburg, Sweden, where the the is monitored.

\section{Super Insulation Materials}

New materials and solutions are being developed that can contribute to improving the energy performance of historic buildings, without altering their character defining elements. Super

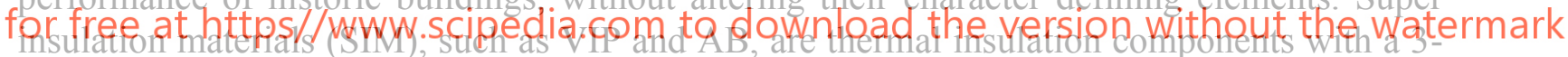

10 times higher thermal resistance than conventional insulation materials, and thus thinner layers can be used. In the IEA Annex 65 'Long-Term Performance of Super-Insulating Materials in Building Components \& Systems' several SIMs were investigated, and case studies were collected from all over the world. More information and conclusions are given by AdlZarrabi et al. (2020). In that project, SIMs were defined by having a thermal conductivity;

- below $25 \mathrm{~mW} /(\mathrm{m} \cdot \mathrm{K})$ if air filled such as aerogel,

- below $20 \mathrm{~mW} /(\mathrm{m} \cdot \mathrm{K})$ if gas filled such as gas filled panel (GFP), and

- below $15 \mathrm{~mW} /(\mathrm{m} \cdot \mathrm{K})$ if evacuated such as VIP.

As mentioned above, two examples of SIM are VIP and AB, see Figure 1. VIP are rigid panels which cannot be cut on site and are sensitive to puncturing. Therefore, attention must be paid in the design of details and envelope components. AB are more like conventional fibrebased insulation materials. They can be cut at the construction site and adapted to the specific measurements. VIP were first tested in buildings in the early 1990s which was later followed by several case studies both in laboratory and in the field while $A B$ have been installed in various building assemblies since the early 2000s (Adl-Zarrabi et al., 2020). 
The long-term performance of SIMs must be determined based on case studies in field and laboratory. Full scale experiments provide knowledge of practical and technical difficulties as well as data for service life estimation. For certain conclusions to be drawn from the case studies, monitoring is essential. Unfortunately, monitoring is only performed in few case studies. These experiences are gathered and evaluated from a long-term performance perspective by Adl-Zarrabi et al. (2020).
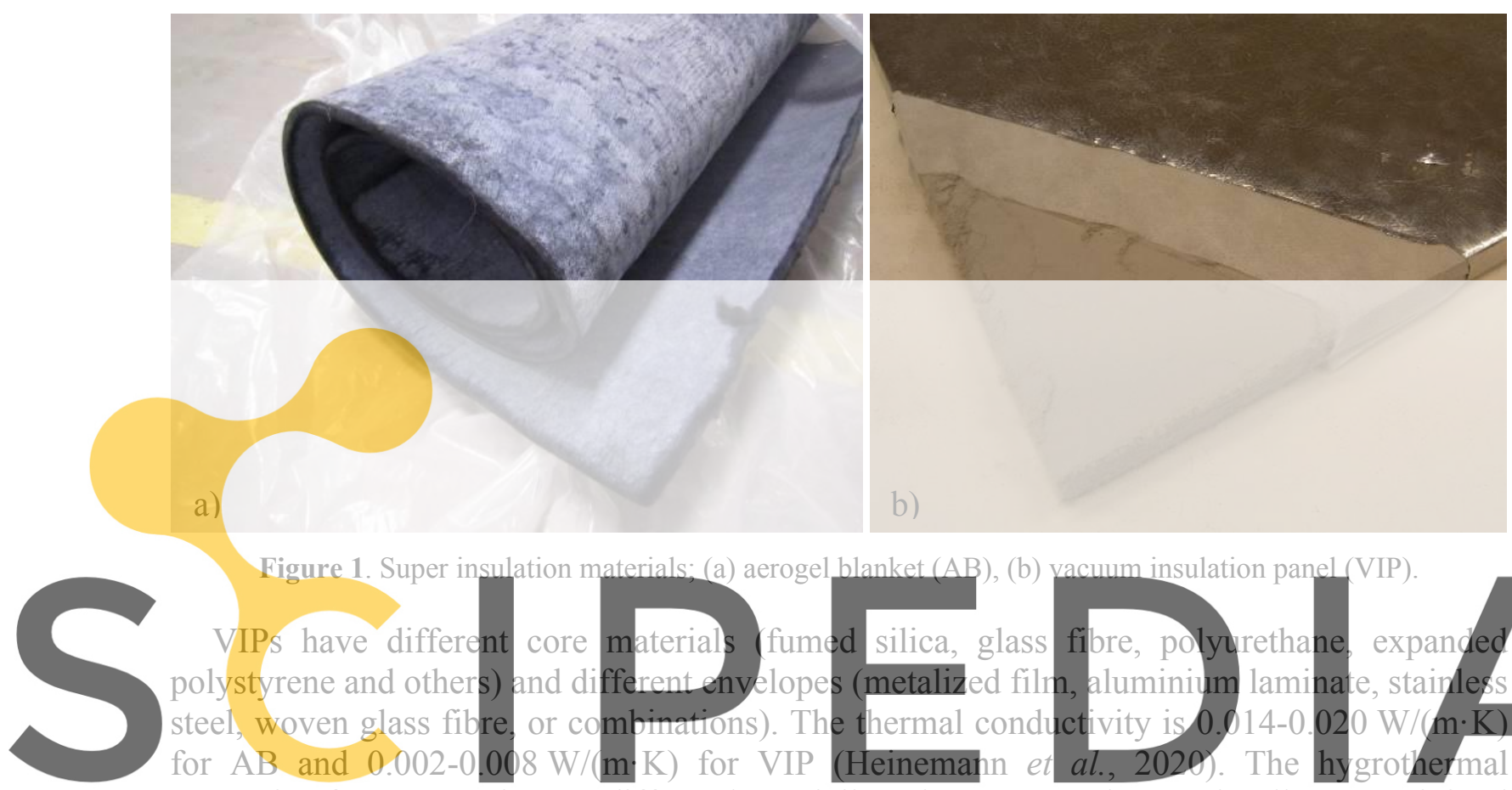

Figure 1. Super insulation materials; (a) aerogel blanket (AB), (b) vacuum insulation panel(VIP).

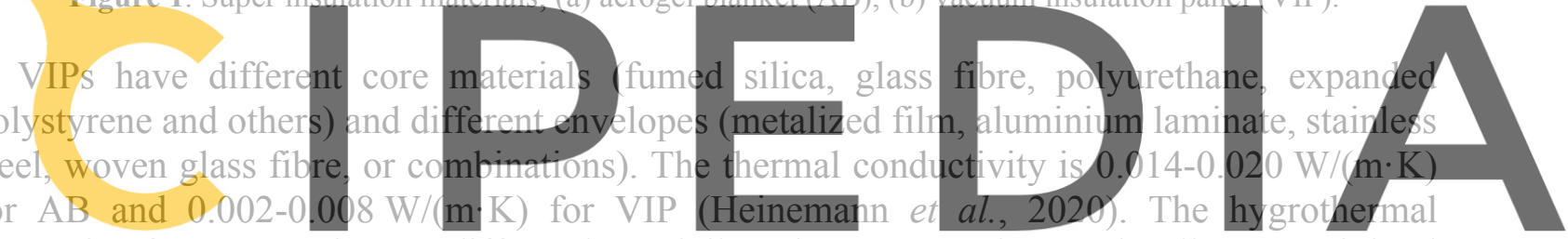

properties for ABs and VIPS differ substantially. The VIP envelope only allows a minimal

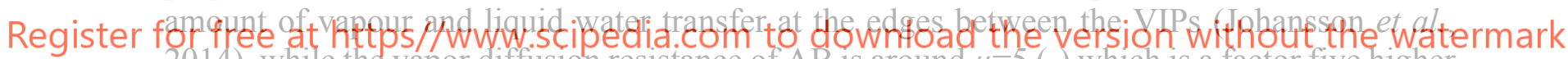
2014), while the vapor diffusion resistance of $A B$ is around $\mu=5(-)$ which is a factor five higher

than mineral wool. The blankets are coated with a water-repellent substance which reduce the liquid water transfer through the material.

\section{Case Study Building}

The case study building, the background and planning of the study is presented together with results from hygrothermal numerical simulations and a laboratory study of interior insulation of a brick wall in Johansson and Wahlgren (2018). The building where the tests are carried out is a long narrow brick and concrete building, once used as a paper machine hall, originally erected in 1896, see Figure 2. The building is one of the oldest in the area. For this case study the conservation officer at the city museum followed up on development of built heritage and monitor that appointed heritage values are being respected in transformation situations.

In the end it was difficult to predict all the uncertainties in the laboratory measurements using the hygrothermal numerical simulations (Johansson and Wahlgren, 2018). The first results from the case study building showed that there was a moisture excess of $0.8 \mathrm{~g} / \mathrm{m}^{3}$ in the building compared to outdoors. Inside a part of the building, a small room $(2.1 \times 2.6 \times 4.0 \mathrm{~m})$ 
was constructed, consisting of floor, walls and roof insulated with $170 \mathrm{~mm}$ mineral wool, and the exposed brick wall with an interior mortar layer. Prior to the installation of the sensors, the existing plaster was removed from the interior brick surface. There was substantial capillary suction from the ground and from the exposure to driving rain from south-west, which is the dominant wind direction. The old plaster was loose up to approximately 1 meter above the concrete slab and came down easily, without applying force, while the upper part of the wall required demolition hammer to remove the plaster. The initial estimations showed that the rate of water flow in the bricks was approximately three times higher than that in modern bricks.

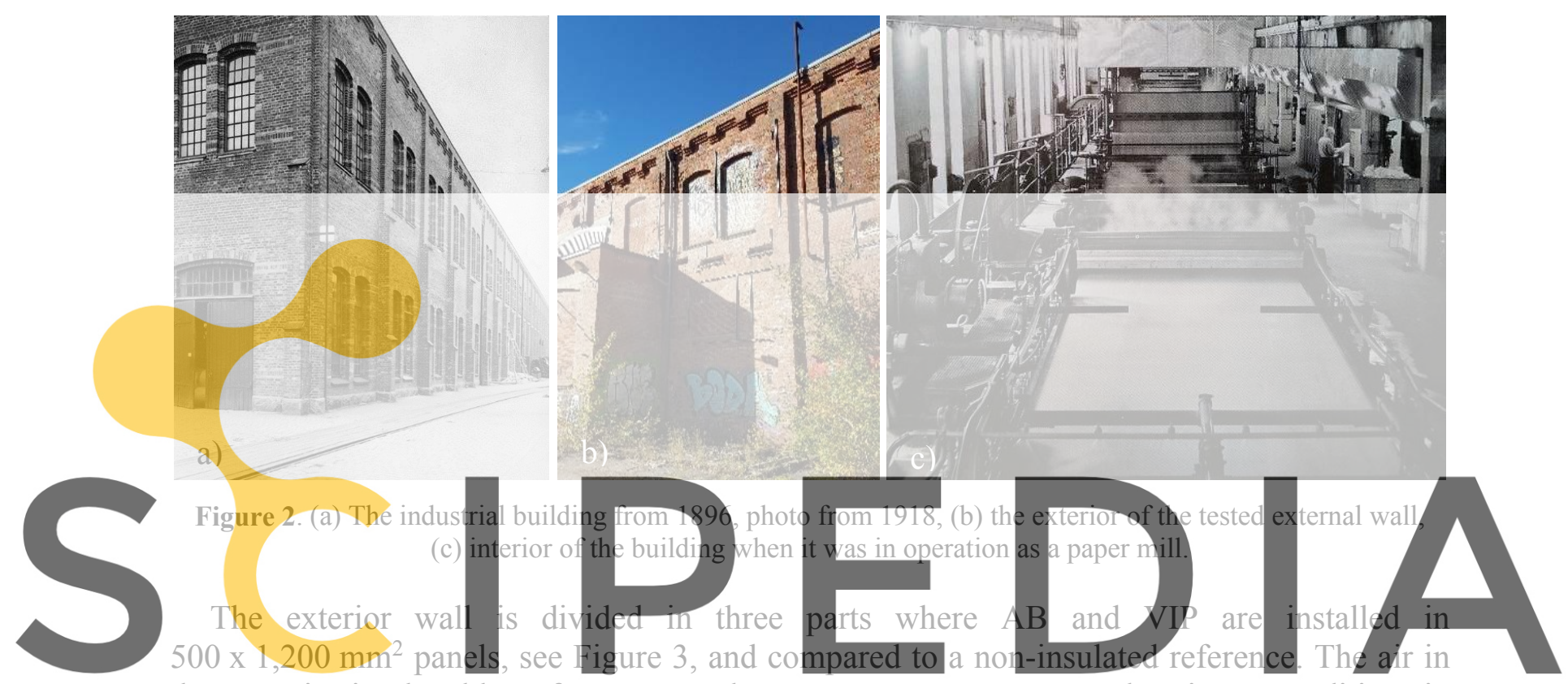

the room is circulated by a fan to create homogenous temperature and moisture conditions in

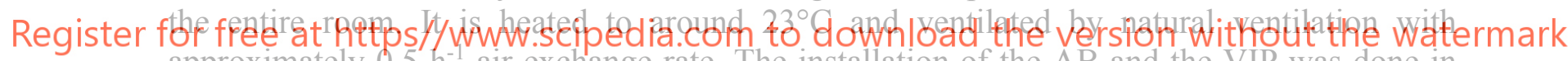
approximately $0.5 \mathrm{~h}^{-1}$ air exchange rate. The installation of the AB and the VIP was done in mid-June, 2018. The temperature and relative humidity of the air is measured by three sensors.

The measurement accuracy is $\pm 2.5 \%$ for relative humidity in the range of 10 to $90 \%$ and $\pm 0.5^{\circ} \mathrm{C}$ for temperature at $25^{\circ} \mathrm{C}$. The temperature can be measured between -40 to $85^{\circ} \mathrm{C}$. There were some initial problems with the equipment and electric power supply which made the indoor temperature vary more than planned.

The heat flux sensor Hukseflux HFP01 (thickness $5.4 \mathrm{~mm}$, diameter $80 \mathrm{~mm}$ ) was used to evaluate the thermal resistance of the wall with and without insulation. The heat flux in $\mathrm{W} / \mathrm{m}^{2}$ is calculated by dividing the voltage output by the sensor's sensitivity. The sensors were calibrated by the producer and delivered with a calibrated sensitivity and calibration uncertainty of $3 \%$ for each sensor. 

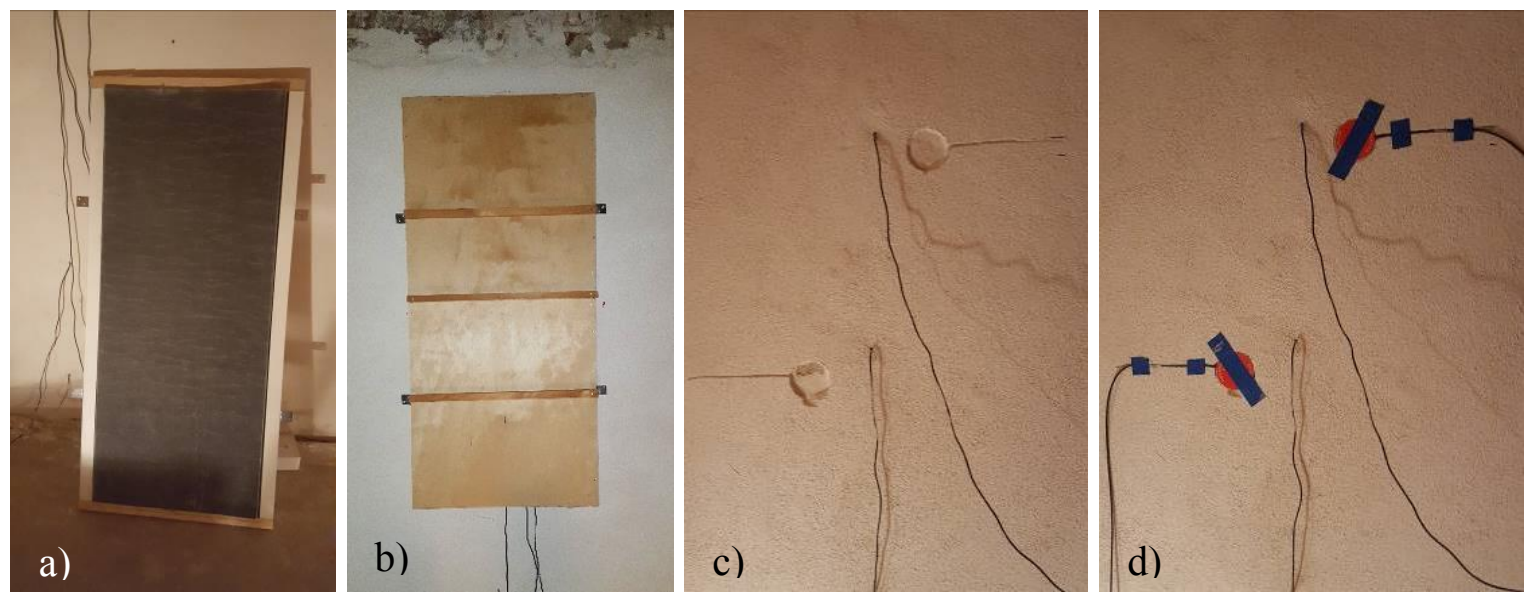

Figure 3. (a) AB insulated panel (removable for inspection), (b) installed AB and VIP panel, (c) before installation of two heat flux sensors inside the mortar layer, and (d) after installation of two heat flux sensors.

The sensor is a thermopile sensor which measures the temperature difference across the ceramic plastic composite body. Air gaps between the sensor and surface of the wall, and between the sensor and the surrounding environment could add additional resistances to the sensor thermal resistance. The sensor was placed in the mortar between the insulation and brick masonry in the wall panels with insulation, while the sensor was facing the indoor environment

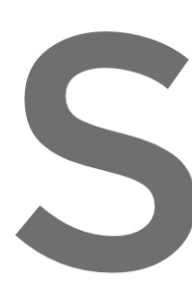
for the wall without insulation
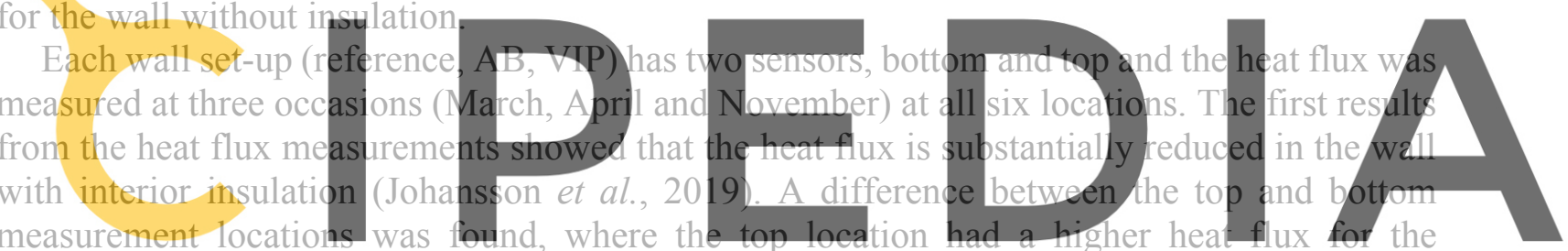

reference wall and the wall panel with VIP, while the wall panel with aerogel had a lower heat

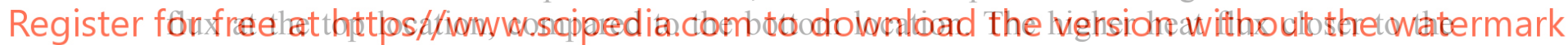
bottom of the wall could be caused by the higher moisture content in the wall closer to the foundation and ground water. The deviation between the different parts of the wall could be explained by the difference in solar radiation between them, where the reference wall is less exposed to solar radiation than the parts with interior insulation. This part of the wall therefore has a higher temperature difference between the interior and exterior surfaces, and consequently a higher measured heat flux which results in a lower U-value (Johansson et al., 2019).

\section{Results from Heat Flux Measurements}

The measured temperature difference between the indoor and outdoor air was averaged over the 3 preceding days due to the high thermal inertia of the brick wall. The thermal inertia was studied numerically by Johansson et al. (2019), where it was concluded that an outdoor air temperature measured for 3 days is enough for the estimation of the U-value from the heat flux measurements. The measurements were performed early in the morning before sunrise, after a cloudy night with stable outdoor temperature. The momentary U-value and percentage difference compared to the reference wall based on the measurements and calculations (following SS-EN ISO 6946:2017) are presented in Table 1. 
Table 1. U-value and percentage difference compared to the reference wall based on heat flux measurements in the brick wall in the bottom and top of the wall. The average outdoor temperature was $5.1^{\circ} \mathrm{C}, 9,7^{\circ} \mathrm{C}$ and $4.5^{\circ} \mathrm{C}$.

\begin{tabular}{ccccccc}
\hline Location & \multicolumn{2}{c}{ March } & \multicolumn{2}{c}{ April } & \multicolumn{2}{c}{ November } \\
\hline Aerogel bottom & 0.310 & $77-84 \%$ & 0.296 & $81-84 \%$ & 0.357 & $70-72 \%$ \\
\hline Aerogel top & 0.292 & $78-85 \%$ & 0.264 & $83-85 \%$ & 0.339 & $71-73 \%$ \\
\hline VIP bottom & 0.308 & $77-84 \%$ & 0.254 & $84-86 \%$ & 0.341 & $71-73 \%$ \\
\hline VIP top & 0.323 & $74-84 \%$ & 0.277 & $82-85 \%$ & 0.358 & $70-72 \%$ \\
\hline Reference bottom & 1.331 & - & 1.549 & - & 1.188 & - \\
\hline Reference top & 1.957 & - & 1.817 & - & 1.269 & - \\
\hline
\end{tabular}

When calculating the U-value of the non-insulated wall based on the thermal conductivity of dry brick $(\lambda=0.61 \mathrm{~W} /(\mathrm{m} \cdot \mathrm{K}))$ and wet brick $(\lambda=1.0 \mathrm{~W} /(\mathrm{m} \cdot \mathrm{K}))$, this results in $\mathrm{U}$-values ranging from 0.997 to $1.476 \mathrm{~W} / \mathrm{m}^{2} \mathrm{~K}$. Corresponding U-values for the part with $20 \mathrm{~mm}$ VIP are 0.264 $0.286 \mathrm{~W} / \mathrm{m}^{2} \mathrm{~K}$ and for the wall with $20 \mathrm{~mm}$ AB the range is $0.394-0.452 \mathrm{~W} / \mathrm{m}^{2} \mathrm{~K}$. The thermal conductivity is also influenced by the temperature. For this case, the influence is negligible as the dependency is typically around $0.0002 \mathrm{~W} /(\mathrm{m} \cdot \mathrm{K}) / \mathrm{K}$ for bricks.

The fact that the measured U-value of the non-insulated wall is lower in November than in March and April can be a result of the wall having dried out during spring and summertime. Since the interior insulation decreases the drying towards the interior side, drying is expected to be significantly slower for these cases, resulting in more moisture, which could explain the smaller variations in U-value for the insulated walls.

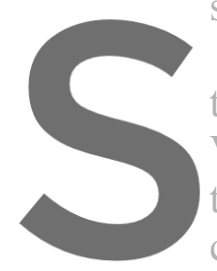

\section{For the wall with} the calculated U-value VIP was up to $35 \%$ hig the measured U-value calculations during all three nets
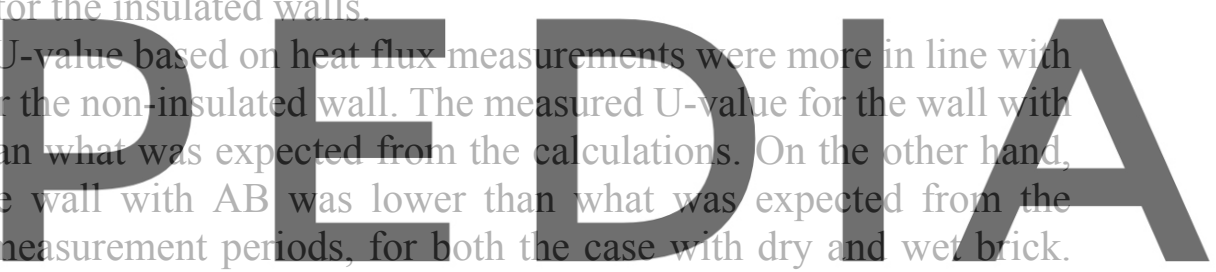

Cuce and Cuce (2016) experienced similar deviations in their study of interior insulation with

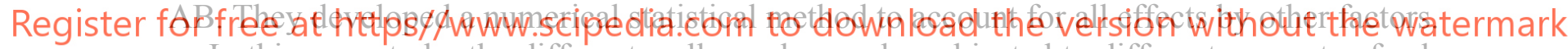

In this case study, the different wall panels may be subjected to different amounts of solar radiation. The wall panel with $\mathrm{AB}$ is most exposed to solar radiation which may have influenced the measurements more here than for the other parts of the wall, resulting in a lower heat flux than expected due to the lower temperature difference (higher outdoor temperature). The other factors that could influence the measurements is the evaporation of water from the wall. This could increase the heat flux by around 5\% which decreases the measured U-value for the reference wall but does not influence the parts of the wall with interior insulation.

One of the studied periods was unusually dry (summer 2018). For this case, the temperature difference between cooler lower parts and slightly warmer upper parts was smaller than other studied periods. This means that there might still be evaporation but that the source might not be rain but possibly evaporation of moisture from the ground. That moisture was rising from the ground was evident from the condition of the wall.

\section{Conclusions}

Many brick buildings in Sweden today face a large need for renovation measures to prolong their service life and make alternative uses possible. In a case study building, interior insulation 
was proposed as a measure for combining energy efficiency and heritage preservation. The $470 \mathrm{~mm}$ homogenous brick masonry wall was investigated regarding the thermal performance of the wall with interior insulation. Earlier research has shown that interior insulation decreases the drying-out capacity of the exterior wall and increases the risk for freeze-thaw damages in brick walls. In this study the building was exposed to both heavy rain and rising ground water. No significant drying took place from the parts with interior insulation and water was added to the wall from the rain outside and through the foundation. Therefore, the owner has now planned to cover the building with an external rain protective envelope Measurements of the heat flux show that additional superinsulation substantially decreases the U-value of the wall. Assuming wet bricks, the average calculated U-value was reduced by $70 \%$ for the AB and $81 \%$ for the VIP layers, while the measurements gave a reduction of $72-83 \%$ for the $\mathrm{AB}$ and $72-84 \%$ for the VIP layers, i.e. the same order of magnitude. With planned measures to make the wall dryer, the interior insulation will be monitored continuously with the aim of contributing to the development of recommendations on how SIMs can be used in historic buildings

\section{Acknowledgements}

This study is supported by the Swedish Energy Agency through the project 42856-1. We would also like to thank MölnDala Fastighets AB and Pontus Johansson, Gabriella Josefsson, Maria Daoud Rajha and Mathis Gelot for performing the laboratory investigations.

\section{ORCID}
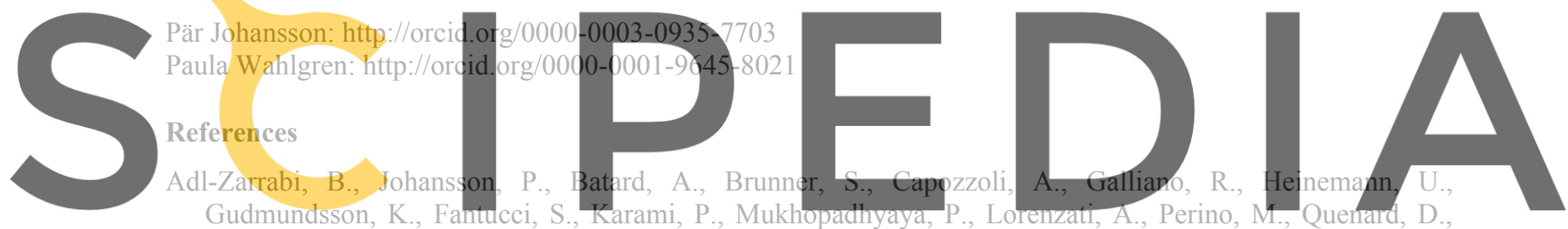
Sprengard, C., Treml, S. and Yrieix, B. (2020). Annex 65, Long-Term Performance of Super-Insulating-

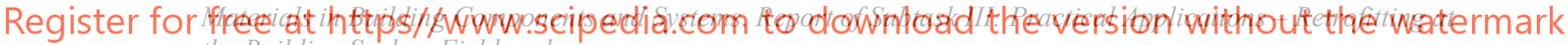
the Building Scale-Field scale.

Boverket. (2018). Klimatdeklaration av byggnader: Förslag på metod och regler. Slutrapport. Rapport 2018:23. Boverket (Karlskrona, Sweden).

Boverket. (2019). Bygg- och fastighetssektorns energianvändning uppdelat på förnybar energi, fossil energi och kärnkraft. Retrieved 7 January, 2020, from https:/www.boverket.se/sv/byggande/hallbart-byggande-ochforvaltning/miljoindikatorer---aktuell-status/energianvandning.

Cuce, E. and Cuce, P. M. (2016). The impact of internal aerogel retrofitting on the thermal bridges of residential buildings: An experimental and statistical research. Energy and Buildings, 116, 449-454.

Heinemann, U, Adl-Zarrabi, B., Brunner, S., Foray, G., Johansson, P., Kono, J., Kücükpinar, E., Milow, B., Quenard, D., Sprengard, C., Wallbaum, H. and Yrieix, B. (2020). Annex 65, Long-Term Performance of SuperInsulating-Materials in Building Components and Systems. Report of Subtask I: State of the Art and Case Studies.

Johansson, P., Geving, S., Hagentoft, C.-E., Jelle, B. P., Rognvik, E., Kalagasidis, A. S. and Time, B. (2014). Interior insulation retrofit of a historical brick wall using vacuum insulation panels: Hygrothermal numerical simulations and laboratory investigations. Building and Environment, 79 (September 2014), 31-45.

Johansson, P. and Wahlgren, P. (2018). Interior insulation retrofit of a brick wall using super insulation materials: design of a field testing in an industrial brick building. In: Proceedings of the 7th International Building Physics Conference, IBPC 2018, Syracuse, NY, USA, September 23-26, 2018. 
Johansson, P., Wahlgren, P. and Eriksson, P. (2019). Field Testing of Interior Super Insulation Materials on a Brick Wall in an Industrial Building. In: Proceedings of the 13th International Conference on Thermal Performance of the Exterior Envelope of Whole Buildings, Clearwater Beach, FL, USA, December 9-12, 2019.

Swedish Energy Agency. (2014). Programbeskrivning för programmet Spara och bevara etapp 3, 2015-01-012018-12-31 (Programme Description for Save and Preserve Stage 3). [In Swedish]. Swedish Energy Agency (Eskilstuna, Sweden).

Swedish Standards Institute. (2007). SS-EN ISO 6946:2007. Building components and building elements - Thermal resistance and thermal transmittance - Calculation method. Geneva, Switzerland: International Organization for Standardization (ISO).
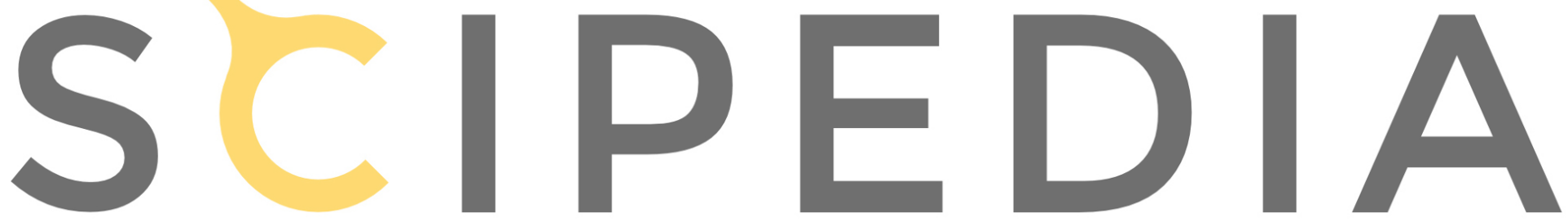

Register for free at https//www.scipedia.com to download the version without the watermark 